\title{
Synthesis of PMMA-b-PEG-b- PMMA by controlled Polymerization
Using Macro-RAFT Agents \\ Mehmet BAĞLAN ${ }^{1}$, Ümit YILDIKO² ${ }^{2}$ İsmail ÇAKMAK ${ }^{1}$, Ahmet Turan TEKEŞ ${ }^{1}$ \\ ABSTRACT: In this work controlled radical polymerization (CRP) of methyl methacrylate was carried out in the presence of the Poly(ethylene glycol)(PEG) xanthate reversible addition fragmentation (RAFT) chain transfer agent designated as $\left(\mathrm{CTA}_{1}\right)$ and $\left(\mathrm{CTA}_{2}\right)$. Firstly, PEGs having different molecular weights $(400$ and $600 \mathrm{~g} / \mathrm{mol})$ were reacted $\mathrm{KOH}$ and $\mathrm{CS}_{2}$ and the terminated 4-chloro benzoyl chloride to obtain PEG-xathates. RAFT agent possessing PEG chain was used in the RAFT polymerization of MMA to yield PMMA-b-PEG-b-PMMA tri-block copolymers which can be used in various potential applications. With the gravimetric follow of the reaction, the control mechanism works well and the molecular weight has grown linearly. The structures of the synthesized macro RAFT agents and polymers were characterized by ${ }^{1} \mathrm{H}-\mathrm{NMR},{ }^{13} \mathrm{C}-\mathrm{NMR}$ and FT-IR spectroscopic methods.
}

Key words: Block Copolymer, Controlled Radical Polymerization, Polyethylene Glycol, RAFT

Mehmet BAĞLAN (0000-0002-7089-7111), İsmail ÇAKMAK (0000-0002-3191-7570), Ahmet Turan TEKEŞ (0000-0002-9942-7367) Kafkas University, Department of Chemistry, Kars, Turkey

2 Ümit YILDIKO (0000-0001-8627-9038), Iğdir University, Tuzluca Vocational High School, Iğdir, Turkey Sorumlu yazar/Corresponding Author: Ümit YILDIKO, yildiko1@gmail.com 


\section{INTRODUCTION}

The properties of the polymers can be changed with the aid of functional groups at the ends of the polymerization ( $\mathrm{Gu}, \mathrm{Xu}$ et al., 2014). This change is usually achieved either by the use of the functional group in initiating the other polymerization or by reaction with polymers having another compatible function (Barsbay and Güven 2018). Because of this reason, intensive studies have been carried out in recent years by means of polymerization methods which have well defined, and some narrow molecular weight and allow the desired functional groups have been added to the structure because of controlled polymerization of polymers. (Hemp, Smith et al., 2014, Ma'Radzi, Sugihara et al., 2014, Li, Ding et al., 2017).

Independed radical polymerization; is a polymerization carried out on easy experimental conditions, in which most of the vinyl monomers can be polymerized with the most industrial applications(Yan, Lin et al., 2017, Liu and Hobbs 2018). Despite all the advantages described above, it is not possible to control the molecular weight, the molecular weight distribution and to obtain polymers prepared at the desired molecular weight in the chain architecture(Beija, Marty et al., 2011). However, by using the case of the living polymerization process it is possible to control and obtain various block copolymers having narrow polydispersity and different chain structure (Foster, Radzinski et al., 2015, Sütekin and Güven 2018).

Among the controlled/living radical polymerization techniques discovered in the last twenty years, nitroxide-mediated polymerization ATRP(Neugebauer 2015, Chmielarz 2016, Liu and Hobbs 2018), nitroxidemediated polymerization, NMP (Nicolas, Guillaneuf et al., 2013, Kermagoret and Gigmes 2016, Ballard, Aguirre et al., 2017)and reversible addition-removal chain transfer (RAFT) (West, Barner-Kowollik et al., 2010, Yeole and Hundiwale 2011, Ma'Radzi, Sugihara et al., 2014, Sütekin and Güven 2018)polymerization techniques have been used extensively in molecular architecture design. Sensitive polymer very welldefined displaying Molecular weight distributions, high end group suitability and various complex architectures are unique for the synthesis of materials. Unlike ATRP or NMP, the RAFT technique does not progress with a reversible termination reaction but is based on a degenerative chain transfer process to provide control. RAFT is defined as one of the most versatile CRP processes because of the availability of virtually all vinyl monomer types, tolerance to various solubilizers and initiators, and (mini-) heterogeneous media such as emulsion or suspension(Yang, Luo et al., 2009, Gu, $\mathrm{Xu}$ et al., 2014). RAFT agent modification can be used to synthesize branched polymers, multi-block, graft, comb or star block copolymers with unique physical properties through chain extension reactions on polymer blocks(Hemp, Smith et al., 2014, Fu, Lei et al., 2017).

In our study, two advantages are offered in terms of synthesis chemistry. The first is the synthesis of RAFT agent containing diblock difunctional polyethylene glycol (PEG), the second is the tri-block copolymer synthesis in which the molecular weight distribution is homogeneous with controlled chain extension. There is little research in the literature with RAFT polymerization for block copolymers using PEG Macro RAFT agents. We anticipate that novel studies will contribute to create infrastructure for creating infrastructure for the preparation of block copolymers with high economic efficiency, preparation of new health, cosmetics and nano technological materials (West, Barner-Kowollik et al., 2010, Fu, Lei et al., 2017).

\section{MATERIALS AND METHODS}

Synthesis of Difunctional Macro Xanthate RAFT Agents: RAFT agents are obtained result of terminating the PEG with aromatic acyl chlorides from the PEG-xanthate salts obtained in the reaction with $\mathrm{CS}_{2}$ and $\mathrm{KOH}$. A series of difunctional xanthate Macro RAFT agents using PEG-400, PEG-600 were prepared as described by Kartal et al., then synthesized according to the reaction given in Fig.1. The overall reaction of the synthesized xanthate Macro RAFT agents is shown in Fig 1.(Kartal et al., 2014)

PEG-400 4-chlorobenzoyl Chloride Macro Xanthate RAFT Agent : ${ }^{1} \mathrm{H}-\mathrm{NMR}(\mathrm{CDCl} 3, \delta$, ppm): 8.0-7.6 (4H, ArH), $4.4(2 \mathrm{H},-\mathrm{OCH} 2), 3.7-3.4(4 \mathrm{H},-$ $\mathrm{CH} 2 \mathrm{CH} 2-)$, ${ }^{13} \mathrm{C}-\mathrm{NMR}$ (CDCl3, $\left.\delta, \mathrm{ppm}\right): 168(1 \mathrm{C},-$ $\mathrm{C}=\mathrm{S}), 164(1 \mathrm{C}, \mathrm{C}=\mathrm{O}), 143$ (1C, C- $\mathrm{CH} 3$,), 133-127 (6C, $\mathrm{Ar}), 72(2 \mathrm{C}, \mathrm{O}-\mathrm{CH} 2), 60$ (2C, -CH2CH2-). FT-IR (n, cm-1): 3069 (-C-H, Ar), 1674 (CHO) 1086 (- C=S).

PEG-600 4-Chlorobenzoyl Chloride Macro Xanthate RAFT Agent: ${ }^{1} \mathrm{H}-\mathrm{NMR}(\mathrm{CDCl} 3, \delta$,ppm): 8.0 7.6 (4H, ArH), 4.4 (2H, OCH2), 3.7-3.4 (4H,CH2CH2-), ${ }^{13} \mathrm{C}-\mathrm{NMR}(\mathrm{CDCl} 3, \delta, \mathrm{ppm}): 168(1 \mathrm{C},-\mathrm{C}=\mathrm{S}), 164(1 \mathrm{C}$, $\mathrm{C}=\mathrm{O}), 143$ (1C, $\mathrm{C}-\mathrm{CH} 3,), 133-127$ (6C,Ar), 72 (2C, $\mathrm{O}-\mathrm{CH} 2), 60$ (2C, $-\mathrm{CH} 2 \mathrm{CH} 2-)$. FT-IR(n, cm-1): 3069 $(-\mathrm{C}-\mathrm{H}, \mathrm{Ar}), 1674(-\mathrm{C}=\mathrm{O})$ 1086 $(-\mathrm{C}=\mathrm{S})$. 


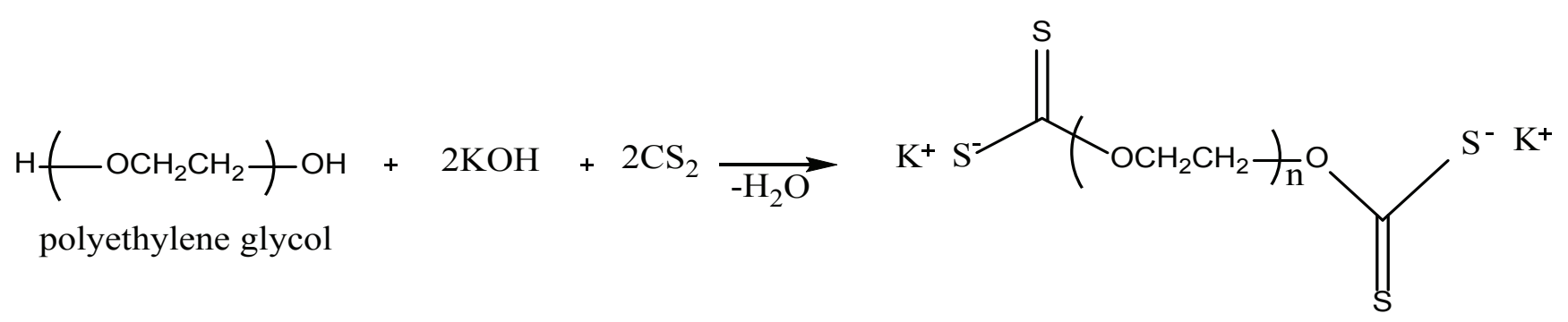<smiles>[Z5]SC(=S)OCCOC(=S)[As][Te]</smiles><smiles>CCOC(=S)SC(=S)OCCOC(=O)c1ccc(Cl)cc1</smiles>

Figure 1. General Synthesis Reaction of Xanthate Macro RAFT Agents

Polymerization of Difunctional Macro Xanthate RAFT Agents with Methyl Methacrylate:

The methyl methacrylate polymerization results of the synthesized macro xanthate RAFT agents resulted in block copolymers of PMMA-b-PEGb-PMMA in different molecular weights. For general polymerizations, [Monomer] was taken as [RAFT agent]: [AIBN] 1000: 8: 1.6. The general polymerization reaction is shown in Figure 2.

Polymerization of PEG-400 4-Chlorobenzoyl Chloride Macro Xanthate RAFT Agent with Methyl Methacrylate: $0.02637 \mathrm{~g}\left(1.606 \times 10^{-4} \mathrm{~mol}\right)$ of AIBN was taken in a beaker and dissolved in 9 $\mathrm{mL}$ of benzene. $9 \mathrm{~mL}$ of distilled methyl methacrylate was stirred over a brief period. This solution was passed through an argon gas to prepare an inert condition. $0.477 \mathrm{~g}\left(6,3002 \times 10^{-4} \mathrm{~mol}\right)$ of PEG-400 4-chlorobenzoyl chloride Macro RAFT agent was added and mixed well to prepare the stock solution. The remaining $18 \mathrm{~mL}$ of solution was taken up with
$2 \mathrm{~mL}$ of each tube and the solutions were again purged with Ar gas and the tubes were capped and sealed thoroughly with paraffin before being allowed to polymerize in a beaker with silicone oil inside at $75^{\circ} \mathrm{C}$. Each tube was taken for 2 hours and precipitated in a beaker containing methanol. Methanol was completely pulled up for the air and allowed to stand in the oven, and the resulting sample was dried in a vacuum oven, and at the end it was transferred into a desiccator until reaching a constant weighing. The experiment reaction is shown in Figure 2. FT-IR(n, cm-1): 3069 (-C-H, Ar), $1674(-\mathrm{C}=\mathrm{O})$ 1086(-C=S).

\section{PEG-600 4-Chlorobenzoyl Chloride} Polymerization of Macro Xanthate RAFT Agent with Methyl Methacrylate: $0.0262 \mathrm{~g}\left(1.596 \times 10^{-4}\right.$ mol) of AIBN was taken in a beaker and dissolved in 9 $\mathrm{mL}$ of benzene. $9 \mathrm{~mL}$ of distilled methyl methacrylate was stirred over a brief period. This solution was passed through an argon gas to make the medium inert. $0.598 \mathrm{~g}\left(6.3002 \times 10^{-4} \mathrm{~mol}\right)$ of PEG-600 4-chloro 
benzoyl chloride Macro RAFT Agent was added to the solution and mixed well.

The remaining $18 \mathrm{~mL}$ of solution was taken up with $2 \mathrm{~mL}$ of each tube and the solutions were again purged with Ar gas and the tubes were capped and sealed thoroughly with paraffin before being allowed to polymerize in a beaker with silicone oil inside at $75^{\circ} \mathrm{C}$. Each tube was taken for 2 hours each and precipitated in a beaker containing methanol. Methanol was completely pulled up to the air and allowed to stand in the oven, and the vacuum was dried in a desiccator until reaching a constant weighing (Figure 2). FT-IR (n, cm-1): $3069(-\mathrm{C}-\mathrm{H}$, Ar), 1674 (CHO) $1086(-\mathrm{C}=\mathrm{S})$.<smiles></smiles>

PMMA-b-PEG-b-PMMA

Figure 2. General Formation Reaction of PMMA-b-PEG-b-PMMA Block Copolymers

\section{RESULTS AND DISCUSSION}

Polymerization of Macro RAFT Agents Containing Polyethylene Glycol (PEG) Based Benzoyl Derivative Xanthate Group with Methylmethacrylate: The experiment results showed that the molecular weight distribution of the polymers obtained by RAFT polymerization is very narrow.

The ln $[\mathrm{M}] \mathrm{o} /[\mathrm{M}]$-Remaining Graph drawn for all polymerisation data, Mn Theoretical -\% Monomer Transformation, Mn Theoretical-Time Graph, Monomer Transformation-Time Graphs were drawn using OriginPro 8 program.
Polymerization of PEG-400 4-Chlorobenzoyl Chloride Macro RAFT Agent with Methylmethacrylate: The reaction conditions and results for the synthesis of the polymerization of PEG400 4-chlorobenzoyl Chloride Macro RAFT agent $\left(\mathrm{CTA}_{1}\right)$ with methyl methacrylate are given in table 1 .

When we observe Table 1, we can clearly see that the weight of polymer was increased over time (Figure 3).

We saw that there is a linear increase by taking Mn theoretical-time values (Figure 4). We observed that monomer conversion increased linearly with Monomer Transformation-Time graph (Figure 5). 
As a result, it is seen that molecular weight control is provided when the tables and graphs of PMMA-
b-PEG-b-PMMA block copolymer obtained are examined.

Table 1. Polymerization Data of PEG-400 4-chlorobenzoyl chloride Macro RAFT Agent with Methylmethacrylate

\begin{tabular}{ccccccc}
\hline $\begin{array}{c}\text { Experiment } \\
\text { N. }\end{array}$ & $\begin{array}{c}\text { Experiment } \\
\text { code }\end{array}$ & $\begin{array}{c}\text { Experiment } \\
\text { Time (h) }\end{array}$ & $\begin{array}{c}\text { Polymer } \\
\mathbf{( g )}\end{array}$ & $\mathbf{l n}_{\mathbf{g}}[\mathbf{M}]_{\mathbf{0}} /[\mathbf{M}]$ & $\begin{array}{c}\mathbf{M}_{\mathbf{n}} \\
\text { Theoric } \\
(\mathbf{g} / \mathbf{m o l})\end{array}$ & $\begin{array}{c}\text { Yield } \\
\mathbf{\%}\end{array}$ \\
\hline 1 & MM-1 & 2 & 0.5165 & 0.51 & 10923 & 39.73 \\
2 & MM-2 & 4 & 0.6889 & 0.76 & 14290 & 52.99 \\
3 & MM-3 & 6 & 0.7293 & 0.82 & 15080 & 56.10 \\
4 & MM-4 & 8 & 0.9480 & 1.31 & 19352 & 72.92 \\
5 & MM-5 & 10 & 1.2456 & 3.07 & 25165 & 95.81 \\
6 & MM-6 & 12 & 1.2518 & 3.25 & 25287 & 96.29 \\
7 & MM-7 & 14 & 1.2867 & 4.87 & 25968 & 98.97 \\
\hline
\end{tabular}

Table 1 gives the results of the experiment conducted about $\mathrm{CTA}_{1}$. As seen in Table1 the RAFT agent was introduced into the polymerization from the initial stage of polymerization and oligomers were formed by adding monomer at both ends in the macro xanthate RAFT agent structure and the polymeric structure size increased linearly after $30 \mathrm{~min}-60 \mathrm{~min}$. This situation is confirmed by Figure 3 and Figure4.In the later stages of the polymerization, the macro-RAFT agent appears to be sensitive and thus appears to result in a good control over the reaction. Since a portion of $\mathrm{CTA}_{1}$ (chain transfer agent) is consumed prior to the start of RAFT polymerization, the ratio of effective monomer to RAFT agent ratio is increased and, as a result, the final polymer distribution will shift towards higher molar masses.

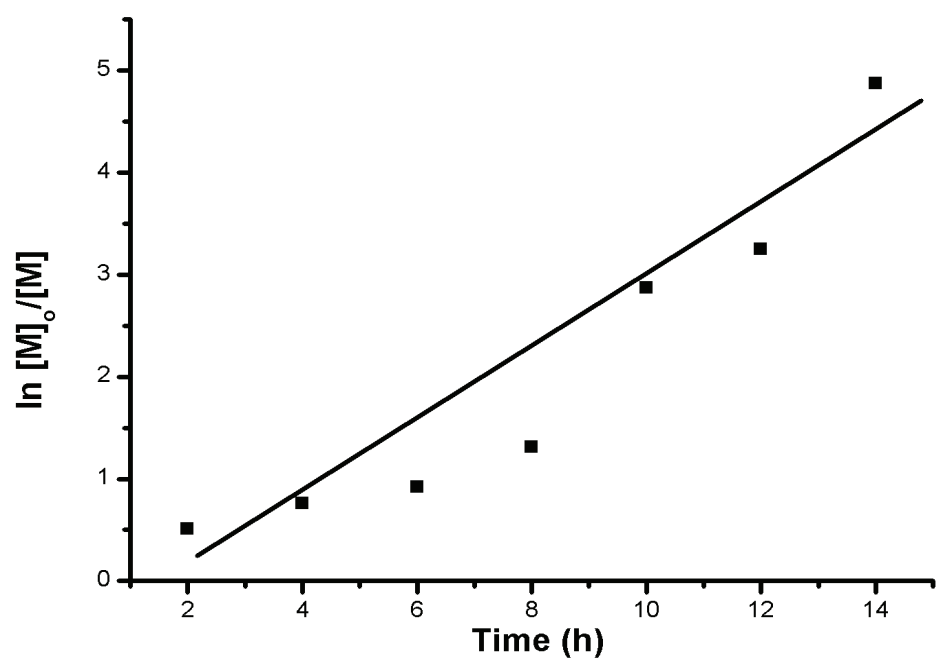

Figure3. Polymerization of PEG-400 4-Chlorobenzoyl Chloride Macro RAFT Agent with Methylmethacrylate ln [M] o / [M] -Time Graph 


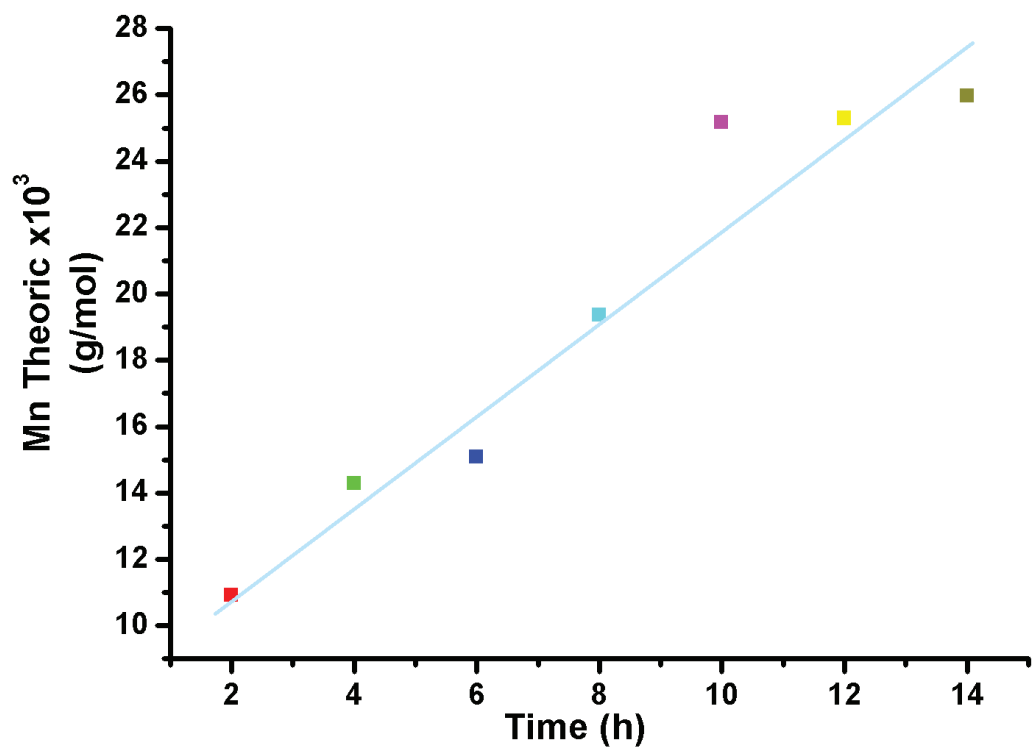

Figure 4. $M_{n}$ Theoretical-Time Graph of Polymerization of PEG-400 4-Chlorobenzoyl Chloride Macro RAFT Agent with Methylmethacrylate

When experimental molecular weight (Mn theoretical) is plotted against monomer conversion, linear correlations have been observed indicating satisfactory controlled polymerization behavior. However, the linearity implies the value of incorporating the monomer into the polymer structure over time. (Figure 4). When the graph is examined, the conversion rate of the monomer consumed between $40 \%$ and $95 \%$ is stable while the addition of monomer after $95 \%$ is decreased.

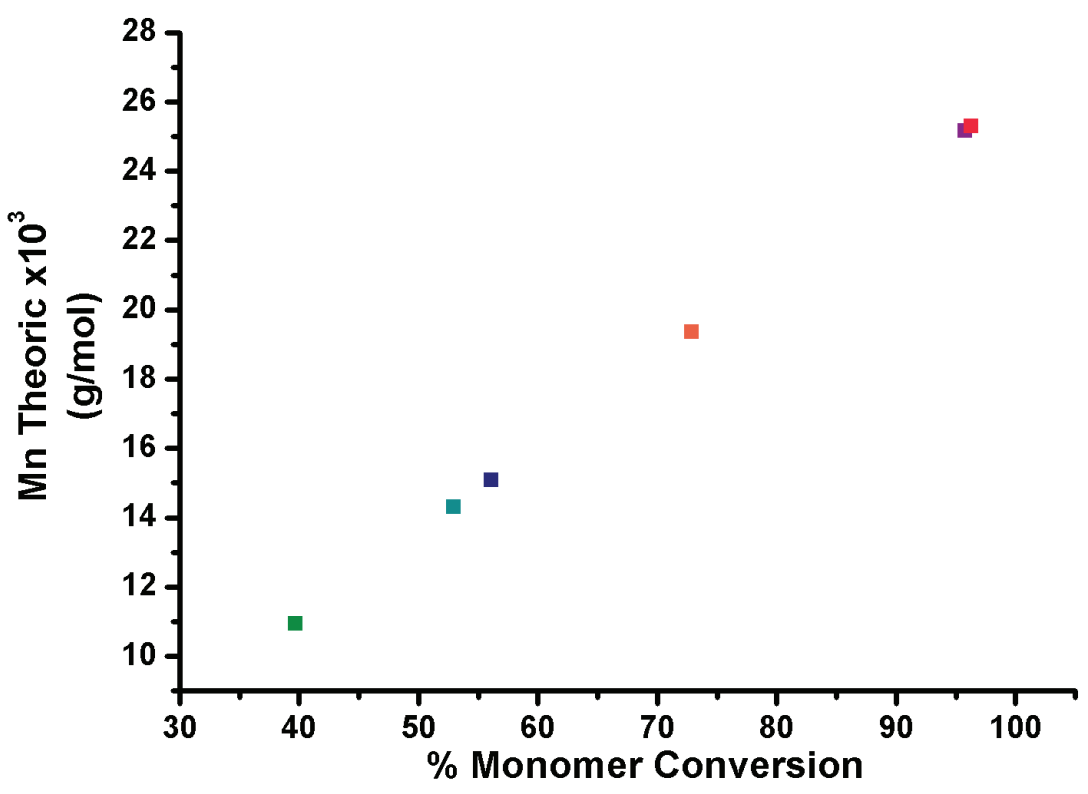

Figure 5. Mn Polymerization of PEG-400 4-Chlorobenzoyl Chloride Macro RAFT Agent with Methylmethacrylate-\% Monomer Conversion

Nevertheless, according to a closer examination of Table 1, in all cases low distributions have been obtained, in other words, the deviation from linearity is small. Over time the increase in monomer conversion showed that the control in the molecular architecture is good. This situation is shown in Figure 6. 


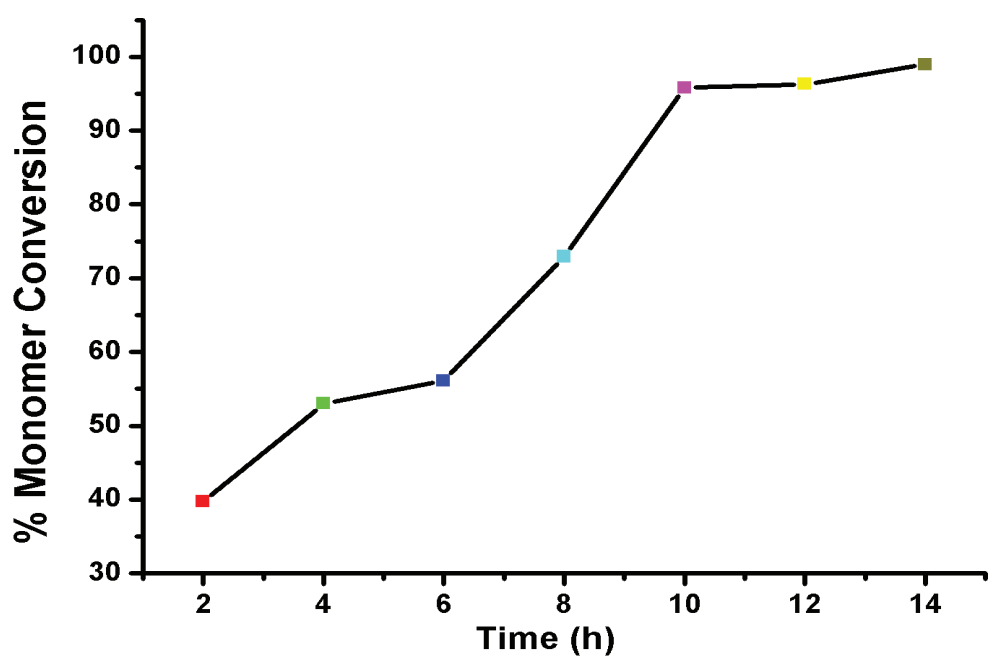

Figure 6. \% Monomer Transformation-Time Graph of Polymerization of PEG-400 4-Chlorobenzoyl Chloride Macro RAFT Agent with Methylmethacrylate

Polymerization of PEG-600 4-Chlorobenzoyl Chloride Macro RAFT Agent with Methylmethacrylate: The reaction conditions and results for the synthesis of the polymerization of PEG-600 4-chlorobenzoyl Chloride Macro RAFT agent $\left(\mathrm{CTA}_{2}\right)$ with methyl methacrylate are given in Table 2 . When we observe Table 2, we can see that the weight of polymer is increased over time (Figure 7). We can see that there is a linear increase by taking Mn theoretical-time values (Figure 8).

We observed that monomer conversion increased linearly with Monomer Transformation-Time graph (Figure 9). As a result, we can see that molecular weight control is provided when the tables and graphs of PMMA-b-PEG-b-PMMA block copolymer obtained are examined.

Table 2. Polymerization Data of PEG-600 4-chloro benzoyl chloride Macro RAFT Agent with Methylmethacrylate

\begin{tabular}{ccccccc}
\hline $\begin{array}{c}\text { Experiment } \\
\mathbf{N} .\end{array}$ & $\begin{array}{c}\text { Experiment } \\
\text { code }\end{array}$ & $\begin{array}{c}\text { Experiment } \\
\text { Time }(\mathbf{h})\end{array}$ & $\begin{array}{c}\text { Polymer } \\
\mathbf{( g )}\end{array}$ & ${\mathbf{I n ~}[\mathbf{M}]_{\mathbf{o}} /[\mathbf{M}]}^{\mathbf{M}_{\mathbf{n}}}$ & $\begin{array}{c}\text { Theoric } \\
(\mathbf{g} / \mathbf{m o l})\end{array}$ & $\begin{array}{c}\text { Yield } \\
\mathbf{\%}\end{array}$ \\
\hline 1 & MB-1 & 2 & 0.1825 & 0.20 & 5246 & 16.59 \\
2 & MB-2 & 4 & 0.2438 & 0.26 & 6660 & 22.16 \\
3 & MB-3 & 6 & 0.4450 & 0.60 & 11306 & 40.45 \\
4 & MB-4 & 8 & 0.6402 & 1.02 & 15814 & 58.20 \\
5 & MB-5 & 10 & 0.8150 & 1.71 & 19849 & 74.09 \\
6 & MB-6 & 12 & 0.9120 & 2.43 & 22086 & 82.90 \\
7 & MB-7 & 14 & 0.9215 & 2.51 & 22307 & 83.77 \\
8 & MB-8 & 16 & 0.9303 & 2.77 & 22511 & 84.57 \\
\hline
\end{tabular}

When the values of Table 2 are examined ( $\mathrm{CTA}_{2}$ ), it is observed that the polymerization has been initiated from the initial stage and oligomer is formed by adding methylmethacrylate at both ends in macroxanthate RAFT agent structure and the polymeric structure dimension linearly increases after $1-3$ hours. However, in the oligomer phase, which is more effective than the $\left(\mathrm{CTA}_{2}\right)$ agent $\left(\mathrm{CTA}_{1}\right)$ agent, it also provides control linearity. This situation is confirmed by Figure7 and Figure8.In the later stages of the polymerization, the macro-RAFT agent appears to be sensitive and thus results in good control of the reaction. 


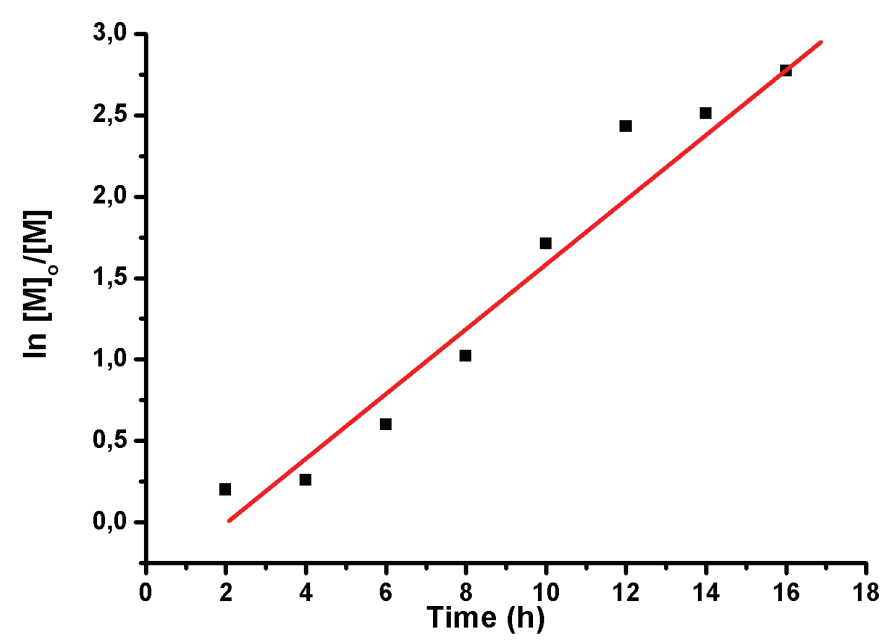

Figure 7. $\ln [\mathrm{M}]_{0} /[\mathrm{M}]$-time Graph of Polymerization of PEG-600 4-Chlorobenzoyl Chloride Macro RAFT Agent with Methylmethacrylate

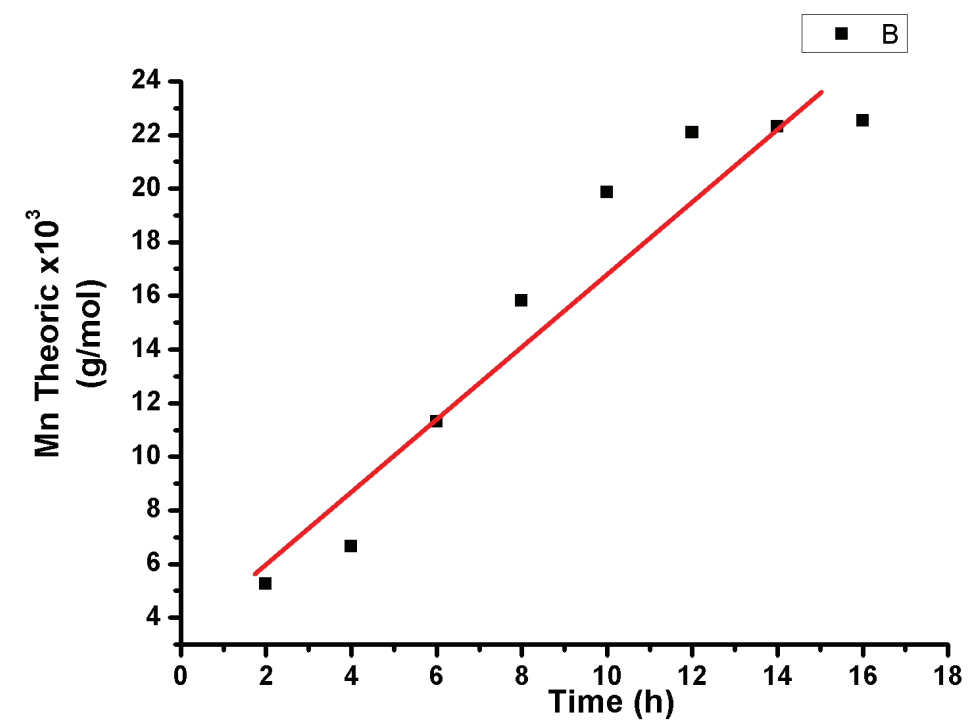

Figure 8. $M_{n}$ Theoretical-time Graph of Polymerization of PEG-600 4-Chlorobenzoyl Chloride Macro RAFT Agent with Methylmethacrylate

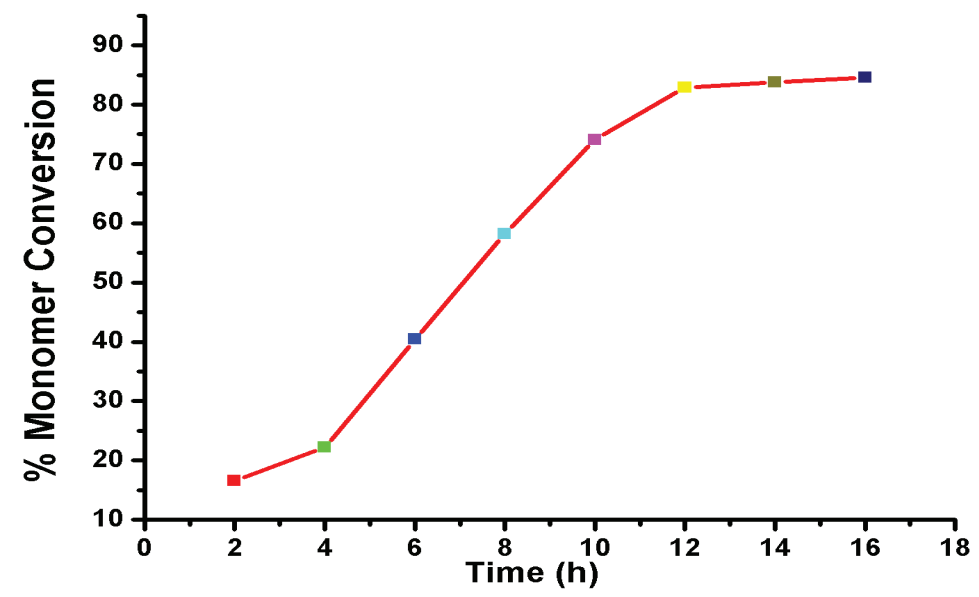

Figure 9. Monomer Transformation-time Graph of Polymerization of PEG-600 4-Chlorobenzoyl Chloride Macro RAFT Agent with Methylmethacrylate 
When experimental molecular weight $(\mathrm{Mn}$ theoretical) is plotted against monomer conversion, a linear correlation has been observed indicating satisfactory and controlled polymerization behavior. Nevertheless, the linearity refers to the value of incorporating the monomer into the polymer structure over time. When Figures 9 and 10 are examined, the conversion rate of the monomer consumed between 20$90 \%$ is stable, whereas the addition of monomer after $90 \%$ is decreased.

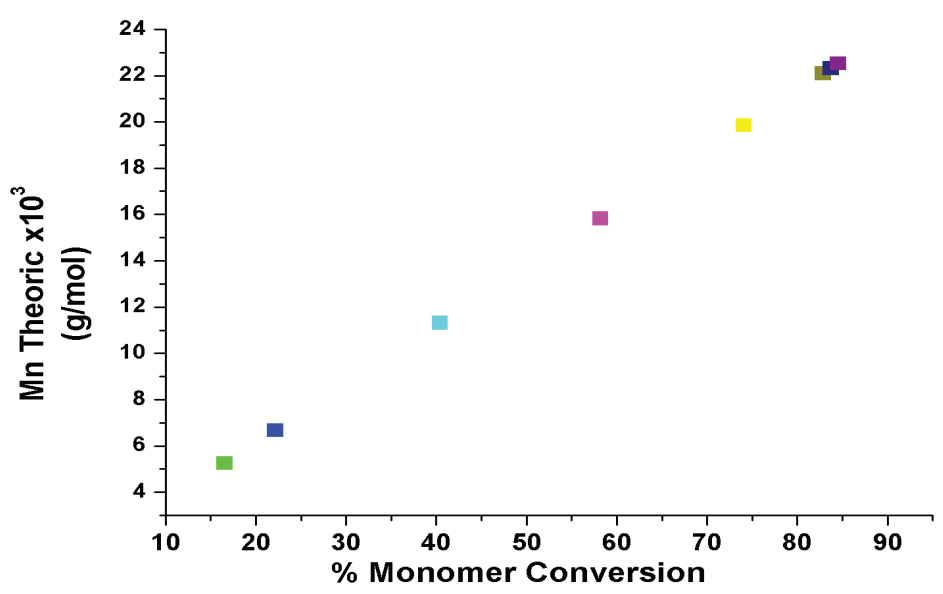

Figure 10. PEG-600 4-Chlorobenzoyl Chloride Macro RAFT Agent Polymerization with Methylmethacrylate Mn Theoretical-\% Monomer Conversion

Synthesis of Macro RAFT Agents Containing Polyethylene Glycol (PEG) Based Benzoyl Derivative Xanthate Group: RAFT agents were formed by aromatic acyl chlorides of PEG-xanthate salts obtained from the reaction of PEG (400-600 $\mathrm{g} / \mathrm{mol})$ with $\mathrm{CS}_{2}$ and $\mathrm{KOH}$. Macro-RAFT agents were characterized by FT-IR, ${ }^{1} \mathrm{H}-\mathrm{NMR}$ and ${ }^{13} \mathrm{C}-\mathrm{NMR}$ spectroscopy. The $\mathrm{OH}$ groups of PEG at $3500-3200 \mathrm{~cm}^{-1}$ when RAFT agents were compared with the PEG FT-IR spectra of the FT-IR spectra showed that the RAFT agents did not completely disappear in the FT-IR spectra and that the PEG did not react during the precipitation of the RAFT agent, it would have been impossible for us to distinguish between the known methods. FT-IR spectroscopy of RAFT agents showed $\mathrm{C}=\mathrm{S}$ groups at $1200-1000 \mathrm{~cm}^{-1}$, and $\mathrm{C}=\mathrm{O}$ groups at $1720-1730 \mathrm{~cm}^{-1}$

The protons of $-\mathrm{CH}_{2}$ in 1-2 ppm in the ${ }^{1} \mathrm{H}-\mathrm{NMR}$ spectra shown in figure 11 and 12 of the RAFT agents, the protons of $\mathrm{CH}_{3}$ in the benzene ring at $2.5 \mathrm{ppm}$, the $-\mathrm{CH}$ protons in the 4,5-5 ppm, $-\mathrm{CH}$ protons of the aromatic structure seen at 7-8 ppm are observed. The peaks at 13 ppm belong to PEG which co-precipitated with RAFT agent during precipitation. The structures of the peaksin Figure 11. confirm that situation explained above.

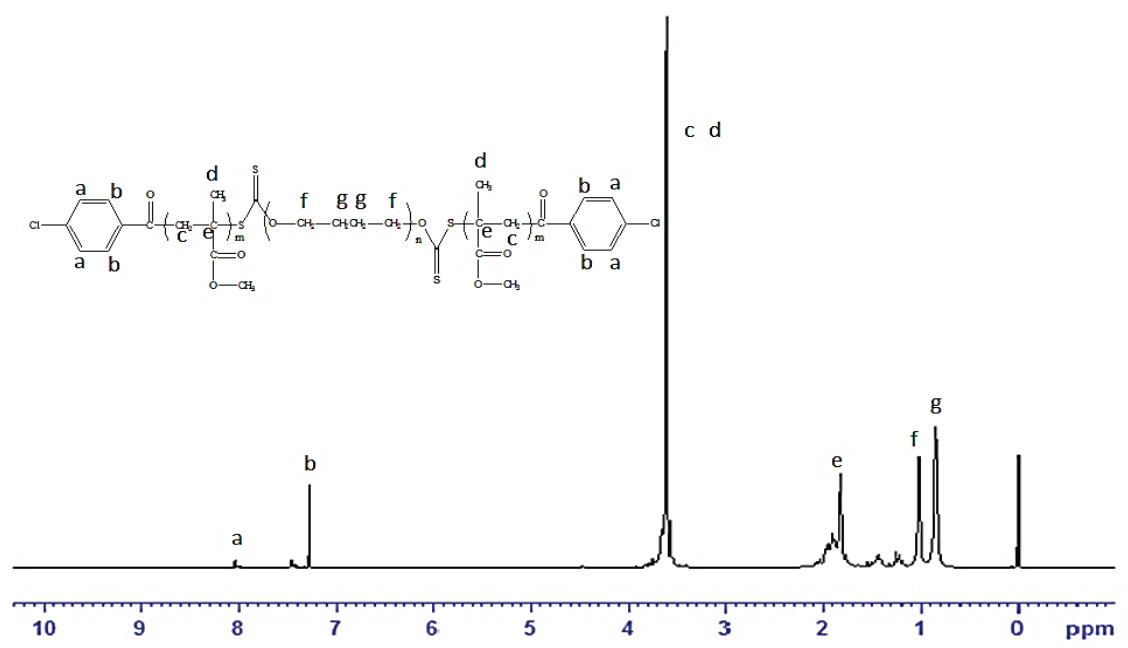

Figure 11. ${ }^{1} \mathrm{H}-\mathrm{NMR}$ Spectrum of Polymerization of PEG-400 4-chlorobenzoyl chloride Macro RAFT Agent with Methyl Methacrylate 


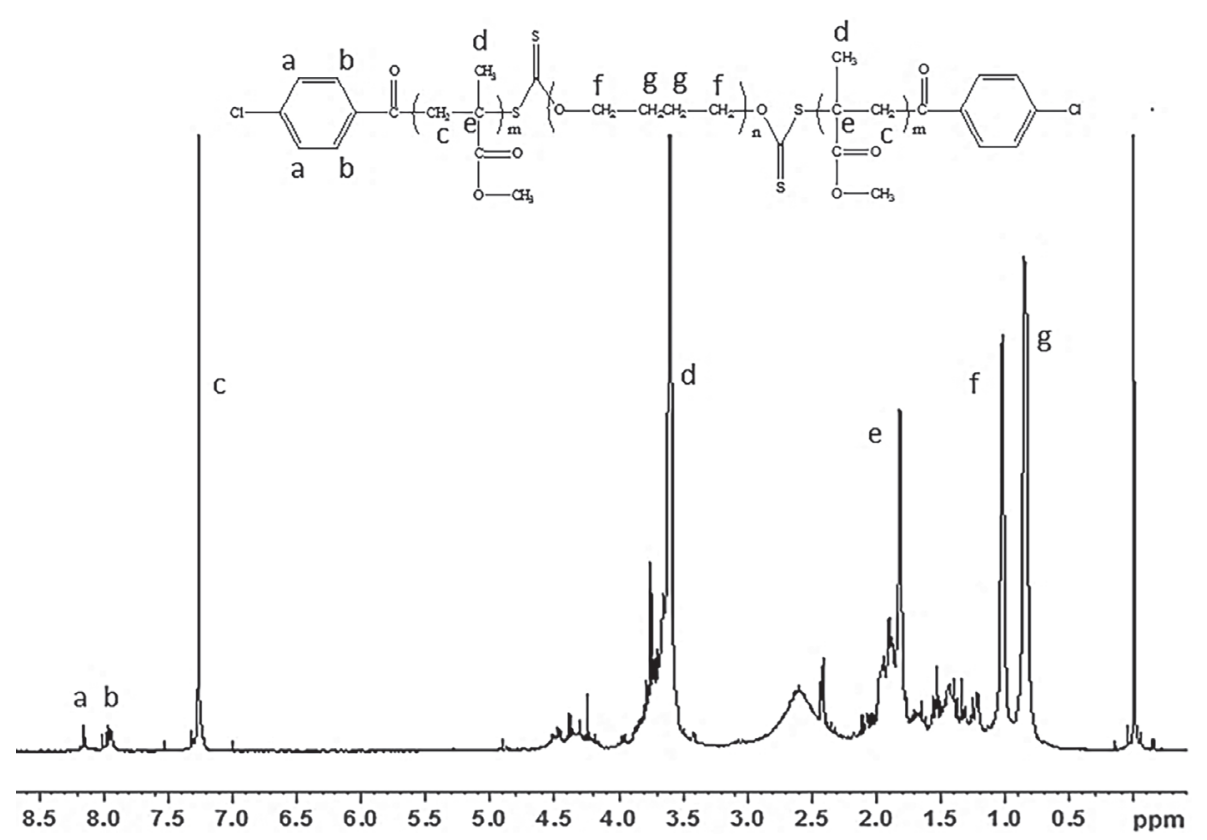

Figure 12. ${ }^{\prime}$ H-NMR Spectrum of Polymerization of PEG-600 4-chloro benzoyl chloride Macro RAFT Agent with Methyl Methacrylate

RAFT agents can be attached to $-\mathrm{CH}_{3}$ groups attached to benzoyl chloride groups at $20 \mathrm{ppm},-\mathrm{CH}_{2}$ groups at $45 \mathrm{ppm}$, - $\mathrm{CHO}$ groups at the $80 \mathrm{ppm}-\mathrm{OCH}$ groups in the aromatic ring at $-30 \mathrm{ppm},-\mathrm{CH}$ groups in the aromatic ring at $80 \mathrm{ppm}$ in the ${ }^{13} \mathrm{C}-\mathrm{NMR}$ spectra shown in Figure 13. and 14. $\mathrm{C}=\mathrm{O}$ groups at $135 \mathrm{ppm}$ and $\mathrm{C}=\mathrm{S}$ groups at $180 \mathrm{ppm}$ are visible. The structures of the peaks that were seen were seen to confirm.

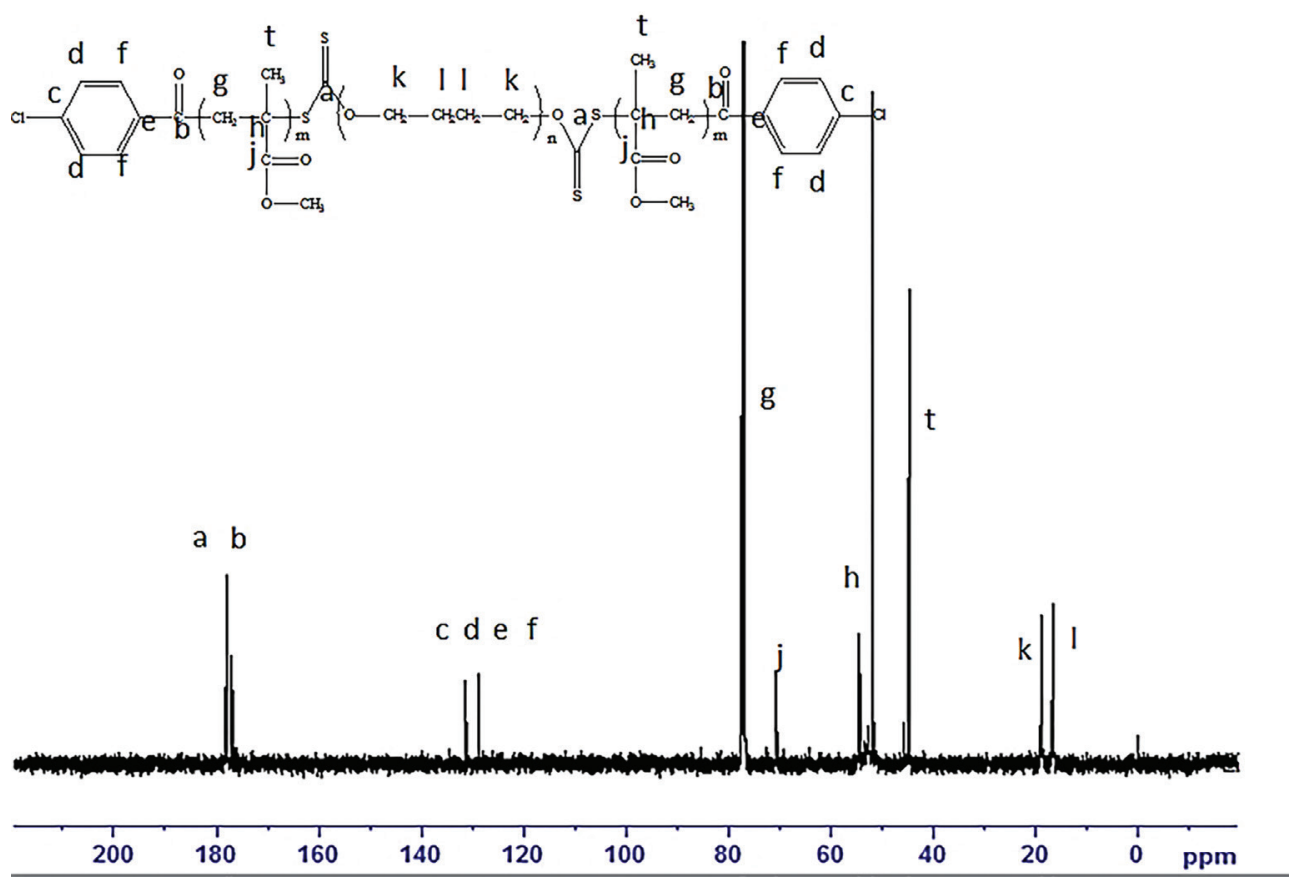

Figure 13. ${ }^{13} \mathrm{C}-\mathrm{NMR}$ Spectrum of Polymerization of PEG-400 4-chlorobenzoyl chloride Macro RAFT Agent with Methyl Methacrylate 


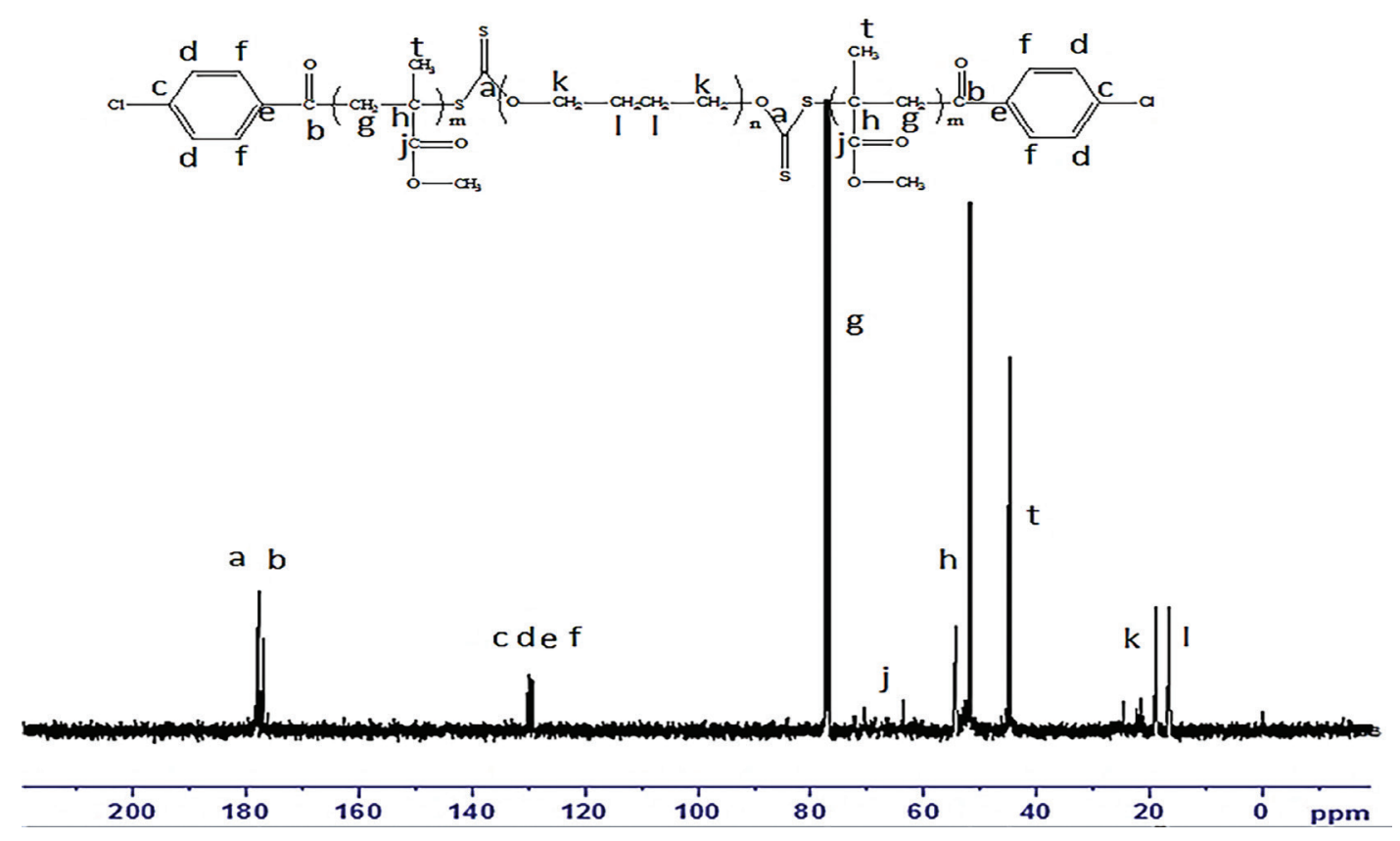

Figure 14. ${ }^{13} \mathrm{C}-\mathrm{NMR}$ Spectrum of Polymerization of PEG-600 4-Chlorobenzoyl chloride Macro RAFT Agent with Methyl Methacrylate

RAFT agents; The end result of the PEG-xanthate salts obtained by reaction of PEG with $\mathrm{CS}_{2}$ and $\mathrm{KOH}$ is terminated with aromatic acyl chlorides. The xanthate salt and RAFT agent were precipitated in a 1: $1(\mathrm{v} / \mathrm{v})$ mixture of diethyl ether and petroleum ether.

\section{RESULTS}

In this study, controlled block copolymers of PMMA-b-PEG-b-PMMA with narrow molecular weight distribution were synthesized using Macro xanthate RAFT agents synthesized. 4-Chlorobenzoyl chloride is attached in terms of chain end functionality.

\section{REFERENCES}

Ballard N, Aguirre M, Simula A, Leiza J R, Es van S, Asua J M, 2017. "Nitroxide mediated suspension polymerization of methacrylic monomers." Chemical Engineering Journal 316: 655-662.

Barsbay M, Güven O, 2018. "Nanostructuring of polymers by controlling of ionizing radiation-induced free radical polymerization, copolymerization, grafting and crosslinking by RAFT mechanism.” Radiation Physics and Chemistry.

Beija M, Marty J.-D, Destarac M, 2011. "RAFT/MADIX polymers for the preparation of polymer/inorganic nanohybrids." Progress in Polymer Science 36(7): 845-886.

Chmielarz P, 2016. "Synthesis of $\alpha$-d-glucose-based star polymers through simplified electrochemically mediated ATRP." Polymer 102: 192-198.
The success of RAFT polymerization depends on the activity of the synthesized RAFT agent. The activity of the R group was best provided by benzoyl chloride when compared to the 4-chloro benzoyl chloride derivatives. In general, the polymerization of macroRAFT agents $\left(\mathrm{CTA}_{1}\right)$ and $\left(\mathrm{CTA}_{2}\right)$ methyl methacrylate with different molecular weights gives a good control of the RAFT agents in the polymerization in which the reaction time is generally short, and similarly long-term polymerizations make it more difficult to control. The resulting polymeric material is important in terms of industry and the use of many fields and the wealth of the literature.

Foster JC, Radzinski SC, Lewis SE, Slutzker MB ,Matson JB, 2015. "Norbornene-containing dithiocarbamates for use in reversible addition-fragmentation chain transfer (RAFT) polymerization and ring-opening metathesis polymerization (ROMP)." Polymer 79: 205-211.

Fu X, Lei Y, Wu B, Chen X, Wang J, Zhou C, Lei J, 2017. "Molecular design and synthesis of acrylic resin film-forming materials with wide applicable temperature range via RAFT emulsion polymerization.” Progress in Organic Coatings 104: 263-270.

Gu R, Xu WZ, Charpentier PA, 2014. "Synthesis of graphenepolystyrene nanocomposites via RAFT polymerization." Polymer 55(21): 5322-5331.

Hemp ST, Smith AE, Bunyard W C, Rubinstein MH ,Long TE, 2014. "RAFT polymerization of temperature- and salt-responsive block copolymers as reversible hydrogels." Polymer 55(10): 2325-2331. 
Kartal B, Yildiko U, Ozturk S, Ata AC, Cakmak I, 2014. 'Study of Solution Polymerization of Styrene in the Presence of Poly(ethylene glycol)-RAFT Agents Possessing Benzoyl Xanthate Derivatives', Journal of Macromolecular Science, Part A, 51: 990-98.

Kermagoret A, Gigmes D, 2016. "Combined nitroxide mediated radical polymerization techniques for block copolymer synthesis." Tetrahedron 72(48): 7672-7685.

Li J, Ding C, Zhang Z, Zhu J, Zhu X, 2017. “Photo-induced reversible addition-fragmentation chain transfer (RAFT) polymerization of acrylonitrile at ambient temperature: A simple system to obtain high-molecular-weight polyacrylonitrile." Reactive and Functional Polymers 113: 1-5.

Liu Y, Hobbs CE, 2018. "Phase-selectively soluble, polymersupported salen catalyst prepared using atom transfer radical polymerization (ATRP).” Polymer 135: 25-29.

Ma'Radzi AH, Sugihara S, Miura S, Konegawa N, Maeda Y, 2014. "Synthesis of thermoresponsive block and graft copolymers via the combination of living cationic polymerization and RAFT polymerization using a vinyl ether-type RAFT agent." Polymer 55(8): 1920-1930.
Neugebauer D, 2015, "Two decades of molecular brushes by ATRP.” Polymer 72: 413-421.

Nicolas J, Guillaneuf Y, Lefay C, Bertin D, Gigmes D, Charleux B, (2013). "Nitroxide-mediated polymerization." Progress in Polymer Science 38(1): 63-235.

Sütekin SD, Güven O, 2018. "Radiation-induced controlled polymerization of acrylic acid by RAFT and RAFT-MADIX methods in protic solvents." Radiation Physics and Chemistry 142: 82-87.

West AG, Barner-Kowollik C, Perrier S, 2010. "Poly(ethylene glycol) as a 'green solvent' for the RAFT polymerization of methyl methacrylate." Polymer 51(17): 3836-3842.

Yan M, Lin F-Y, Cochran E W, 2017. "Dynamics of hyperbranched polymers derived from acrylated epoxidized soybean oil." Polymer 125: 117-125.

Yang L, Luo Y, Liu X, Li B, 2009. "RAFT miniemulsion polymerization of methyl methacrylate." Polymer 50(18): $4334-4342$

Yeole N, Hundiwale D, 2011. "Effect of hydrophilic macro-RAFT agent in surfactant-free emulsion polymerization." Colloids and Surfaces A: Physicochemical and Engineering Aspects 392(1): 329-334. 